\title{
A INTERPRETAÇÃO DE TEXTOS E A FORMAÇÃO DA PESSOA REFLEXIVA - SOBRE A CONCEPÇÃO DEWEYANA DA LEITURA
}

\author{
José Cláudio Morelli Matos *
}

\begin{abstract}
RESUMO
Por meio do exame do pensamento de John Dewey, sobretudo das obras Democracia e educação (1916) e Como pensamos (1910-1933), discutese uma concepção acerca da leitura e interpretação de textos. O papel educacional da leitura é destacado por meio de uma identificação desta atividade com o que Dewey denomina de "pensamento reflexivo". Assim, não haveria oposição entre a pedagogia da experiência de Dewey e uma forte tonalidade pedagógica atribuída à leitura. $\mathrm{O}$ resultado da prática da leitura é a formação de hábitos mentais mais integrados, maior aproveitamento da energia dispensada, e aumento das chances do comportamento bem sucedido, de acordo com os objetivos que os próprios agentes estabelecem. A leitura é compreendida como investigação, direcionada a apreender o significado do texto. Este último é compreendido como um artefato, ou utensílio, constituído a partir dos símbolos escritos. Por ser um utensílio, se presta a um uso individual e social. No ambiente social em que a linguagem escrita ocupa papel determinante na conduta bem sucedida dos indivíduos, a leitura é fundamental instrumento de comunicação por meio do qual as crenças, conhecimentos, modos de agir são transmitidos e modificados.
\end{abstract}

Palavras-chave: Leitura. Dewey. Reflexão. Comunicação.

\begin{abstract}
By an examination of John Dewey's thought, especially of the works Democracy and education (1916) and How we think (1910-1933), is discussed a conception about reading and interpretation of texts. The
\end{abstract}

\footnotetext{
* Doutor em Filosofia pela Universidade de São Paulo (USP). Professor de Filosofia da Educação na Faculdade de Educação da Universidade do Estado de Santa Catarina (UDESC). E-mail: doutortodd@gmail.com
} 
educational role of reading is remarked by an identification of this activity with what Dewey names "reflective thought". So, there is no opposition between Dewey's pedagogy of experience and a strong pedagogic shade attributed by him to reading. The result of the practice of reading is the formation of more integrated mental habits, better use of dispended energy, and increasing of ways to well succeeded behavior, in accord to the aims established by the agent himself. The reading is understood as investigation, directed to apprehend the meaning of the text. This is understood as an artifact or utensil, constituted from wrote signs. Being a utensil, it is able to an individual and social use. In an environment in wich written language occupies a determinant role in the individual's successful conduct reading is a fundamental instrument of communication, by means of wich beliefs, knowledge and ways of acting are passed on and modified.

Keywords: Reading. Dewey. Reflection. Communication.

\section{Introdução}

A leitura é uma atividade de tal importância cognitiva e social que justifica a preparação e o exercício de situações em que é justamente a própria capacidade de ler que está sendo ensaiada e exercitada. Mesmo após o letramento - com efeito, principalmente então - o leitor continua a se formar por meio do que se tem chamado de "hábito da leitura". É comum ver-se a leitura como uma habilidade que, uma vez adquirida, é utilizada para diversos propósitos: recreativos ou produtivos, individuais ou coletivos. Por isso reconhece-se facilmente que é preciso treinar, praticar, desenvolver, aprofundar a própria habilidade de leitura.

O resultado deste desenvolvimento da leitura é a formação de hábitos mentais mais integrados, menos dispersos, maior aproveitamento da energia dispensada, e aumento das chances do comportamento, individual ou coordenado socialmente ser bem sucedido, de acordo com os objetivos que os próprios agentes estabelecem, naquilo que envolve a leitura. Sobre este último ponto, acrescenta-se que a própria ação de formular e estabelecer claramente quais são seus objetivos - os objetivos a que um indivíduo vai dedicar seu tempo e recursos - depende cada vez 
mais da capacidade de lidar de modo desenvolto e hábil com um ambiente feito, em parte, de textos que demandam uma leitura competente.

No contexto da filosofia da educação de John Dewey observa-se uma valorização da atividade do educando,e de seu contato com situações e com objetos que despertem nele o interesse genuíno na atividade a ser desenvolvida. Dewey chega a afirmar que a educação é um processo constante, que se identifica com o próprio processo de crescimento da vida. Vide, por exemplo, seu discurso nos capítulos iniciais de seu tratado Democracia e educação (1916). Na profunda ligação entre a vida, entendida como processo de crescimento da experiência, e a educação como condutora deste processo, é que se apóia o sentido mais rigoroso atribuído pelo autor ao termo "educação".

Chegamos assim a uma definição técnica de educação: é uma reconstrução ou reorganização da experiência, que esclarece $e$ aumenta o sentido desta e também a nossa aptidão para dirigirmos o curso das experiências subseqüentes (DEWEY, 1959, p. 83, ênfase no original).

O termo "educação" é dotado de um sentido muito profundo para Dewey, que aponta para relações com outros processos de crescimento, de reconstrução do comportamento em função da necessidade de uma bem sucedida adaptação dos indivíduos ao meio ambiente natural e social em que se encontram (MATOS, 2010). Por isso, a educação é considerada responsável por desenvolver nos indivíduos as habilidades e disposições necessárias ao contínuo crescimento da experiência pessoal e social.

\section{Uma concepção específica acerca da leitura}

Todos os motes desta teoria da educação, conhecida por sua inspiração naturalista, são muito bem conhecidos dos estudiosos. Mas tal imagem do pensamento de Dewey suscita uma questão: qual o papel pedagógico desempenhado pela leitura e interpretação de textos neste projeto educacional, que pretende significar - conforme o autor acentua em diversas passagens de sua vasta obra - um crescimento dos sujeitos 
para a vida democrática? Dewey ressalta a importância do envolvimento do educando em atividades que guardem relação com sua experiência e interesses. Será que Dewey estaria propondo uma pedagogia que se lance a outras atividades para exercitar o pensamento - e por este meio formar a pessoa reflexiva - pretendendo reservar menos tempo e menos atenção à atividade de leitura ou interpretação de textos, ao longo do processo educativo?

A fim de discutir este assunto com a profundidade e o cuidado que ele merece, não há outra maneira de recorrer ao testemunho do autor a não ser a própria leitura de seus textos. Assim, a presente reflexão é - ela própria - uma espécie de leitura: uma indagação que busca a solução de uma dificuldade, de um problema de conhecimento, seguindo as sugestões enunciadas pelos argumentos e ideias presentes no conjunto dos escritos do autor.

Antes de prosseguir é preciso fazer um esclarecimento sobre a terminologia aqui empregada. O termo "leitura" está sendo usado no sentido de um tipo bem específico de "interpretação", ou seja, esforço intelectual de atribuição de significado a objetos que atuam como signos, ou símbolos, com o objetivo de compreender e, portanto, ser capaz de fazer uso destes objetos. Quando se diz "leitura", não se está utilizando o termo em sentido amplo e genérico, mas no sentido da interpretação dos símbolos linguísticos componentes de um texto, estruturados de forma a veicular um significado compreensível pelo leitor. Sobre isso, José Morais, em seu livro $A$ arte de ler (2002), faz uma importante ressalva. Seu objetivo é guardar o sentido da palavra "leitura" especificamente para a investigação do sentido de textos escritos, e não para a reflexão geral sobre quaisquer objetos da experiência. Em suas palavras:

Para compreender o que é a leitura temos que evitar estender o campo de aplicação do nosso objeto de estudo. Aumentando a extensão do conceito, alguns pensam certamente em aumentar sua importância. Dessa maneira, na verdade, não se saberia mais o que exatamente se estuda. O próprio objeto se diluiria, perderia o que tem de específico, de intrinsecamente interessante (MORAIS, 2002, p. 15). 
Admitindo o que Morais afirma, segue-se que, embora a reflexão e a investigação sejam atividades intelectuais que podem se voltar a qualquer objeto de conhecimento, ainda assim, guardamos o termo "leitura", como é razoável, para referir-se ao processo de pensamento reflexivo cujo objetivo é a interpretação de segmentos definidos de texto escrito.

Segue-se, finalmente, a indicação do próprio Dewey de que o texto escrito, como todo complexo de símbolos da linguagem, é um instrumento, um artefato, do qual o intérprete, por meio da leitura, está fazendo uma utilização. Um símbolo não é apenas uma coisa: "Um símbolo, ao contrário, é, como todo instrumento, todo utensílio artificial, projetado, inventado, para o fim de transmitir um significado" (DEWEY, 1979, p. 229). Ler, neste sentido, envolve simultaneamente a ação de deixar-se conduzir, de abrir-se e submeter-se ao que o texto quer dizer, e ainda a ação de instituir, de estabelecer um uso e um significado apropriados, conforme o texto e conforme o leitor que a ele se dirige.

Outro autor, considerado por muitos como um descendente intelectual de Dewey, que manifesta concepção semelhante é Daniel Dennett. Em seu artigo The interpretation of texts, people and other artifacts (1990), ele se refere aos textos como artefatos cuja origem intencional pode ser usada para guiar a sua interpretação. Ele afirma que:

naturalmente, algumas leituras são melhores do que outras - isto é, mais interessantes, mais coerentes, mais ricas, menos ad hoc, melhor informadas - mas nenhuma leitura possui o privilégio de ser isolada como o real significado do texto (DENNETT, 1990, p. 179).

Curiosamente, Dennett considera que os próprios leitores são artefatos, cuja capacidade de ler e interpretar é formada ao longo de inúmeras gerações de aperfeiçoamento, no processo evolutivo natural e cultural. Mas este assunto merece um tratamento mais demorado, que não é o propósito principal deste estudo.

O que especificamente nos interessa é que, como artefato, o texto é relativamente autônomo. O texto é autônomo no sentido de que pode ser lido e interpretado segundo sua própria estrutura de razões. A autonomia é um modo de enfatizar a relação direta entre o texto e o leitor, numa leitura que não depende de intermediários. Depois que o texto foi escrito e tornado 
público, ele não pertence mais ao seu autor, do que a qualquer outro leitor. O próprio autor é somente mais um leitor do texto - como o inventor da chave inglesa vem a ser só mais um usuário desta ferramenta - uma vez que este texto foi constituído como um artefato, ou utensílio, acessível publicamente. Isto é o que significa dizer que o texto é autônomo.

\section{A questão da leitura no pensamento de Dewey}

Ao discutir o emprego educacional da leitura, Dewey aponta para o risco de que uma educação focada na cultura escrita se afaste do fluxo da experiência individual, e traga com isso a consequência de, além de se tornar fastidiosa e desinteressante, se tornar também ineficaz como fator de crescimento. Sobre isso ele diz:

Quando as palavras não entram como fatores em uma ação compartilhada - quer real, quer imaginariamente - elas obram como puros estímulos físicos, não tendo significação ou valor intelectuais (DEWEY, 1959, p. 17).

Palavras e discursos que não forem incorporados ao sentido da experiência individual e social não representam potencialidade educativa, porque não atendem ao interesse genuíno do sujeito. Este é o risco que correm os procedimentos e práticas de leitura nos processos educacionais. Mais ainda, o discurso escrito consolidado na tradição, as obras do passado, os tratados e peças literárias que formam o legado cultural em meio escrito, correm ainda outro risco, na visão do autor:

Incorporadas à linguagem, as idéias dos outros substituem as nossas próprias idéias pessoais. Ao protestar contra a predominância da linguagem nas escolas, os reformadores tinham em mente o uso de estudos e métodos verbais que fazem o espírito humano parar no nível das realizações do passado (DEWEY, 1979, p. 234).

Esta segunda advertência diz respeito mais à atitude mental envolvida no processo da leitura, do que ao contexto ou situação em que a leitura é empregada no processo educacional. $\mathrm{O}$ risco sofrido pelo 
educando é o de assimilar tantas ideias prontas, e de modo tão dogmático, que ficaria impedido de desenvolver as suas próprias.

Por tudo isso, poder-se-ia indagar: Haveria, portanto, alguma espécie de oposição entre o lema principal do naturalismo deweyano de "aprender pela experiência" e o lema tradicionalmente conhecido e seguido, de "aprender por meio de textos"? Este problema precisa ser considerado, sobretudo, em uma época onde a leitura tem se tornado um problema pedagógico e social da maior relevância. Uma época onde o volume de informação - melhor dizendo - o volume de experiência humana acumulada que é veiculado em linguagem escrita é cada vez maior.

William Kilpatrick, pensador da educação comprometido com o pensamento de Dewey, reconhece este crescimento do valor social da escrita e da leitura na contemporaneidade, ao afirmar que: "Foi graças ao prelo moderno, especialmente em suas formas mais recentes, e aos modernos meios de transporte, que a própria influência da palavra escrita se tornou mais intensa" (KILPATRICK, 1978, p. 19). Em sua obra Educação para uma civilização em mudança (1926), este se refere à importância da palavra escrita no contexto das transformações sociais da sociedade industrial e científica. Ao fazer isso, sua posição encaminha-se no mesmo sentido das reflexões aqui propostas, sobre a fundamental importância educativa da leitura. Kilpatrick, seguindo Dewey, ressalta a presença cada vez mais volumosa de informação escrita, como parte do contexto experiencial da sociedade contemporânea. Sem sequer imaginar o salto evolutivo representado pelo aparecimento das tecnologias de informação e comunicação, já chamava atenção para a influência da palavra escrita e a correlata necessidade de interpretá-la e utilizá-la de forma desenvolta.

Uma abordagem naturalista da situação do homem no mundo tem sido tentada por muitos pensadores, desde que a descrição detalhada da natureza, mais particularmente do lugar ocupado nela pelo ser humano, tornou possível examinar em detalhe as suas consequências em diversos campos do conhecimento. Falando em termos mais precisos, a visão da vida fornecida pelo paradigma darwiniano tornou possível uma compreensão do ser humano que viabilizou a compreensão da mente, da linguagem e da cultura, como estruturas resultantes de um desenvolvimento que possui raízes cravadas no processo mais amplo de evolução, a que estão sujeitos todos os seres vivos. 
Autores influentes no pensamento filosófico têm examinado as possibilidades de reflexão nascidas da abordagem naturalista. No caso de Dewey, trata-se de um discurso em que a questão da educação desempenha um papel central. A educação formal, como meio da transmissão e da renovação da vida, depende de modo inescapável da linguagem, com mais ênfase na linguagem escrita. Portanto, ao abordar a leitura sob a perspectiva do pensamento de Dewey, é preciso levar em conta o ponto de vista naturalista. Isso conduz inevitavelmente a compreender a leitura como uma habilidade individual e social que tem sua origem e sua função descritíveis em termos evolutivos. Tal conclusão significa, sobretudo, que a habilidade intelectual da leitura é concebida a partir do crescimento gradual e seletivo de habilidades e disposições. Estas mesmas habilidades e disposições que fazem sentido para o investigador, como estruturas que promovem a adaptação e interação dos indivíduos no meio social.

Ora, uma das principais tendências naturais, desenvolvidas ao longo do processo evolutivo nos seres humanos é justamente o pensamento. Dewey aborda este assunto na obra Como Pensamos (publicada inicialmente em 1910, e revisada em 1933), afirmando categoricamente que o pensamento parte de tendências inatas, embora necessite de exercício e de controle pedagógico para apresentar-se em sua forma mais desenvolvida (DEWEY, 1979, p. 23).

\section{Leitura e pensamento reflexivo}

O que está sendo proposto aqui é que a leitura seja entendida como um processo de pensamento. Se isso está correto, é possível supor que, assim como há formas mais e menos encadeadas de pensamento, há formas mais e menos encadeadas de leitura. Neste sentido, quando o texto é um objeto de interesse, e quando o seu significado representa motivo de questionamento, a leitura é um exercício - mais precisamente - daquilo a que Dewey chama de pensamento reflexivo.

Diante de uma situação de dúvida, de indeterminação ou incerteza, a mente que reflete busca intencionalmente por qualquer indício que possa representar o caminho para uma resposta, uma solução. Estes indícios são o que Dewey chama de "sugestão". As sugestões são efeito de objetos, 
ou aspectos dos objetos que chamam a atenção de quem está pensando, e indicam uma linha, um rumo que o pensamento segue. Por exemplo, a nuvem carregada sugere a ideia de chuva ao observador.

Ao percorrer um texto, acompanhando e decifrando seu sentido, o leitor reflexivo está seguindo sugestões, atribuindo a elas deferentes valores, conforme sua própria experiência e conforme a situação na qual elas se apresentam. A descoberta desta solução, por sua vez, caracteriza a consumação de uma experiência que a relação com o texto provoca. Este processo de pensamento, descrito nas palavras de Dewey, se apresenta assim:

Compreenderéapreenderasignificação.Enquantonãocompreendemos, ficamos, se nos assalta a curiosidade, inquietos, desorientados, e, por isso, inclinados a pesquisar. Depois que compreendemos, sentimo-nos, por assim dizer, intelectualmente em casa (DEWEY, 1979, p. 135).

Dewey não está se referindo especificamente à compreensão do texto, mas sempre à apreensão do significado por meio da investigação. Quando se propõe, como é aqui o caso, tratar a leitura como investigação do texto, naturalmente não se está com isso supondo que toda atividade de leitura seja investigativa em igual medida, assim como não se poderia supor que todo pensamento fosse reflexão numa mesma medida. Mais ainda: outras modalidades de pensamento - como o devaneio ou a fantasia - possuem ocasiões e finalidades apropriadas na vida mental dos sujeitos. Bem como outras modalidades de leitura, mais espontâneas, são possíveis e até desejáveis em vista da diversidade de ocupações e interesses, numa relação saudável com diversas espécies de textos escritos.

Contudo, é somente o pensamento reflexivo que caracteriza um controle ativo e ordenado do indivíduo sobre o objeto do pensamento. Do mesmo modo, a leitura reflexiva se exerce na busca ativa e ordenada do esclarecimento dos significados presentes no texto. Tal leitura é uma experiência intelectual, cujo resultado é o estabelecimento de uma relação comunicativa na qual o leitor participa ativamente do interesse e dos significados transmitidos pelo texto. É também seu resultado a elucidação de um problema constituído na relação com o texto. Esta situação tende a 
ser tanto mais interessante para o leitor, quanto mais à experiência da leitura estiver em conexão com outros aspectos de seu contexto experiencial.

Dewey afirma sobre o pensamento reflexivo que:

A necessidade da solução de uma dúvida é o fator básico e orientador em todo o mecanismo de reflexão. Quando não se trata de um problema a resolver ou de uma dificuldade a superar o curso de nossas sugestões flui ao acaso (DEWEY, 1979, p. 24).

Pode-se dizer o mesmo com respeito à reflexão empreendida na interpretação de um texto escrito. Quando não há interesse pela solução da questão contida no texto, quando a compreensão não é buscada a fim de satisfazer a curiosidade, as sugestões fluem ao acaso e a utilização do texto pelo leitor é casual e fortuita. Por outro lado, na investigação, a sugestão e a curiosidade, associados ao interesse pessoal ou social, dirigem o pensamento em busca do significado. E neste caso, o utensílio representa para o usuário uma ocasião de prática da reflexão em busca da compreensão. Pelo que se conclui que nada impede de considerar a leitura - neste sentido - como investigação.

Pode-se, em acordo com Dewey, atribuir duas qualidades à experiência da leitura, que fazem dela uma atividade essencialmente educativa: primeiro a leitura é um veículo de transmissão da herança social acumulada, veiculada no texto. Segundo, a leitura é uma ocasião de prática do pensamento reflexivo. O pensamento que opera a leitura não se volta apenas para uma situação individual, mas para uma estrutura de significados publicamente acessíveis e socialmente compartilhados que se encontram formulados em linguagem escrita.

O próprio Dewey, em Como pensamos, discute a importância da formação educativa da pessoa capaz de refletir de modo desenvolto. Se o argumento de que a leitura caracteriza o exercício desta modalidade de pensamento for aceito, naturalmente que a prática e o aperfeiçoamento da capacidade de ler e interpretar deve constituir um fim educacional. Aqui não se trata, contudo, da alfabetização ou do letramento, entendidos principalmente como aquisição da capacidade de identificar o símbolo e seu referente. Trata-se de um investimento na prática de uma atitude investigativa, o que é bem diferente. 
No capítulo 7 de Como pensamos, intitulado Análise do ato de pensar reflexivo, Dewey aborda o uso de textos escritos no exercício do pensamento. O que há de mais interessante em seu discurso é sua consideração das obras de literatura e poesia, como instrumentos intelectuais para a reflexão sobre a realidade. $O$ tratamento dado pelo autor a este assunto fortalece o ponto de vista desenvolvido neste trabalho: o de que a leitura e a interpretação de textos é um exercício de investigação e de pensamento e, portanto, merece ser considerado como um ingrediente essencial na formação da pessoa reflexiva. Segundo ele:

Muitas idéias são de grande valor como elementos da poesia, da ficção ou do drama, mas não como matéria do conhecimento. Todavia, desde que se conservam na mente para serem utilizadas à luz de novos fatos, as idéias poderão constituir um instrumento intelectual para um espírito penetrante, mesmo que não se relacionem imediatamente com a realidade (DEWEY, 1979, p. 111).

Veja-se que Dewey menciona o valor das ideias presentes no texto literário, como objetos que um "espírito penetrante" pode relacionar proveitosamente com assuntos da experiência concreta do leitor. $\mathrm{O}$ espírito formado nos hábitos de investigação, de exercício da consciência reflexiva, é o que se pode sem dúvida supor que Dewey esteja considerando como "penetrante". Pois é por meio do pensamento reflexivo que o indivíduo é capaz de penetrar, compreender e dar tratamento intelectual aos problemas com que se depara.

Pelo que tem sido discutido, encontra-se uma resposta em Dewey para a primeira questão enunciada acima, acerca da relevância da leitura de obras escritas para sua proposta educacional. Esta resposta soluciona uma dificuldade, mas só o faz por meio de propor novas dificuldades de maior complexidade. Que operação, ou conjunto de operações a leitura envolve? Como se equilibram os aspectos emocionais e intelectuais no processo da leitura? Em que medida uma teoria acerca da leitura está conectada a uma teoria a respeito de seu agente, o leitor? Talvez seja isso o que o próprio Dewey quisesse dizer com o critério de continuidade da experiência, segundo o qual uma experiência é educativa quando ocasiona ou cria 
condições para a ocorrência de mais amplas experiências. A experiência de refletir sobre a importância atribuída por Dewey à leitura conduz, em continuidade com ela, para a experiência de indagar mais profundamente sobre a concepção mantida por Dewey acerca desta mesma atividade - a leitura.

Esta segunda família de perguntas possivelmente envolve aspectos de caráter mais abstrato e, por isso, neste momento, toda resposta que se pode oferecer é apenas uma indicação. A elucidação de uma concepção de leitura no pensamento deweyano necessitaria, para ser profunda e detalhadamente tratada, de um percurso mais longo, de uma mais extensa investigação. No presente momento, o que se pode fazer são alguns apontamentos das direções em que, na filosofia de Dewey, um estudioso poderia seguir para refletir acerca da concepção deweyana da leitura.

$\mathrm{O}$ primeiro deles refere-se à qualidade da experiência e ao processo de pensamento reflexivo tão enfatizado pelo autor. A leitura crítica, aquela que representa uma experiência integral de solução para um problema, é um processo de investigação - ao que tudo indica - cujos resultados estabelecem as condições para a experiência subsequente. Esta parte da resposta foi debatida acima, com a tentativa de defender uma aproximação entre a leitura e o pensamento reflexivo.

O segundo apontamento refere-se à comunicação. A teoria deweyana da comunicação possui um aspecto ambiental e comportamental muito marcante que se aplica, naturalmente, ao caso da leitura. A leitura, por isso, é diferente do isolamento e da atividade meramente subjetiva ou individual. A leitura, quanto mais bem sucedida em seus objetivos, é uma intercomunicação, é tomar parte de uma experiência cultural acessível a muitos, que, por meio do texto expressam e reconhecem aspectos comuns em sua experiência.

\section{Leitura e comunicação}

Educar fazendo uso de todos os instrumentos de que uma sociedade dispõe, a fim de desenvolver hábitos e capacidades para o uso da inteligência, de modo a dirigir a conduta; educar de modo a conduzir o indivíduo a participar das ações que visam o interesse socialmente compartilhado; 
educar visando o modo de vida democrático. Tudo isso parece envolver uma relação hábil, desenvolta, competente, reflexiva do indivíduo em relação aos textos escritos. É isto o que leva Dewey a afirmar que "em uma cultura adiantada, muito do que se tem de aprender se encontra armazenado em símbolos" (DEWEY, 1959, p. 9). Em uma educação progressiva, a leitura ganha importância, seu papel se torna mais - e não menos - decisivo para a consideração inteligente do que é experimentado no processo de transmissão da vida social por meio do símbolo escrito. Dewey, em uma de suas principais obras - Democracia e educação - refere-se à linguagem escrita como a invenção que tornou possíveis os processos formais de educação. A educação formal, da qual a escola é a principal representante, baseia-se em grande medida na capacidade de compreensão e análise de textos escritos. Assim é que podemos compreender o sentido da seguinte passagem:

Desde que a linguagem representa as condições físicas que sofreram a máxima transformação no interesse da vida social - coisas físicas que perderam sua qualidade originária tornando-se instrumentos sociais - é natural que a linguagem represente grande papel, comparado ao dos outros recursos. Por meio dela, em caráter de substitutos, conseguimos participar largamente da passada experiência humana, dilatando e enriquecendo assim a experiência do presente (DEWEY, 1959, p. 41).

Os artefatos humanos construídos com os símbolos da linguagem são veículos dos conhecimentos, experiências e valores acumulados e selecionados pelo rigoroso teste da adaptação ao ambiente social. Com a linguagem escrita, em especial, são produzidos a todo momento instrumentos de pensamento, de apreciação estética, de instrução e até de doutrinação, que permanecem disponíveis para serem utilizados em novas situações e novos contextos ambientais. Deste modo, mesmo que a organização das palavras e frases escritas permaneça a mesma, a interpretação deste legado fixado na linguagem vai se modificando, conforme se modificam as condições sociais e individuais de sua utilização pelos diversos indivíduos que com ele tem contato. 
Falando mais especificamente acerca deste contato dos indivíduos com os significados constituídos na linguagem escrita, Dewey acrescenta:

Por infinitos meios a linguagem condensa significações que registram resultados sociais e pressagiam perspectivas sociais. De tal arte ela importa em uma liberal participação em tudo o que é de valor na vida, que iletrados e não educados passaram quase a ser duas expressões sinônimas (DEWEY, 1959, p. 41).

Vemos, por meio desta passagem, a consciência que Dewey manifesta acerca da importância da linguagem e, em especial, da linguagem escrita. Os dois elementos educativos mais destacados nesta passagem, e em geral em toda a compreensão que o autor mantém do assunto, são os já mencionados: de que a linguagem é meio de comunicação de uma - vasta - porção da experiência humana e de que a linguagem é instrumento do pensamento reflexivo. Estes elementos são constituintes do caráter educativo da linguagem, e se tornam acessíveis ao sujeito por meio da educação.

A teoria da comunicação presente na obra de Dewey tem sido recentemente alvo da atenção de estudiosos, em vista das inúmeras possibilidades abertas por esta teoria para a reflexão sobre a linguagem, o pensamento e os mecanismos de coordenação da conduta social. Sobretudo, com o avanço das ciências cognitivas e dos estudos acerca da mente, nos últimos anos, o pensamento de Dewey passa a ser visto como um precursor de diversas ideias, envolvendo a comunicação. Recentemente, Gert Biesta (2006), em um artigo intitulado "'Of all affairs, communication is the most wonderfull': the communicative turn in Dewey's Democracy and education", analisa a posição de Dewey enfatizando o quanto a concepção deweyana da comunicação é marcada por um aspecto de conduta socialmente compartilhada. Biesta interpreta o pensamento de Dewey como o de que:

comunicação é um processo de coordenação social ou que este processo não apenas efetua o entendimento comum em um mundo comum e compartilhado, mas é também a origem da reflexão e da consciência reflexiva (BIESTA, 2006, p. 27). 
Assim, não é o caso de que indivíduos inteligentes e autônomos iniciem a comunicação em um ambiente social compartilhado e préexistente. Tanto a individualidade, como a inteligência, e mesmo a própria existência de um ambiente social no qual possam os indivíduos interagir; tudo isso é efeito e não condição da comunicação, segundo esta leitura da visão de Dewey.

De todo o conjunto de processos que constituem a comunicação, parte se realiza na interação entre indivíduos fisicamente próximos ou contemporâneos, mas, nas sociedades cuja vida se torna mais complexa, estes processos envolvem lidar com uma função cujo projeto alcança uma extensão relativamente maior, tanto espacial como temporalmente - a leitura. Por isso, a leitura permanece como uma atividade eminentemente educativa. A aquisição de uma competência elevada em sua prática, portanto, habilita o indivíduo a participar de inúmeros interesses sociais. O que, invariavelmente, envolve a formação de hábitos apropriados a este desempenho e a esta competência.

\section{O ambiente social e a leitura}

Toda esta reflexão faz ainda mais sentido se considerarmos a tonalidade ambiental da concepção deweyana sobre o ser humano. Dewey enfatiza em inúmeras ocasiões a importância fundamental da interação com o ambiente na formação dos hábitos e, em última instância, da mente individual. Este processo de formação não é apenas um crescimento de potencialidades internas, mas constitui literalmente uma compreensão, um crescimento, uma resposta ativa do indivíduo a situações de que fazem parte os interesses e significados compartilhados com outros.

A direção social consiste, realmente, nos hábitos de compreensão que se estabelecem usando-se os objetos em correlação com outras pessoas, quer pela cooperação e auxílio, quer pela rivalidade e concorrência. $\mathrm{O}$ espírito ou a mente como coisa concreta, é precisamente a faculdade de compreender as coisas tendo em vista o uso feito das mesmas (DEWEY, 1959, p. 35, grifos do autor). 
Este crescimento que dá como resultado a formação da mentalidade é sempre efetuado por intermédio do meio. É por isso que nenhuma influência direta poder ser observada entre um indivíduo e outro. "O fato é que não existe influência direta de um ser humano sobre outro, independentemente do uso do ambiente físico como intermediário" (DEWEY, 1959, p. 30). Todo efeito educativo, todo efeito comunicativo, para falar em termos mais gerais, é sempre exercido através do meio. Um dos instrumentos mais elaborados com o qual se opera neste meio, como sabemos, é a linguagem. E de todas as formas de acesso a este instrumento, a mais elaborada é a leitura.

Em um ambiente onde o sucesso dos indivíduos em satisfazer suas necessidades depende, sobretudo, dos mecanismos de força física, associados aos mecanismos de controle físico, uma das preparações importantes, principalmente para os mais jovens, é participar de situações em que estes mecanismos de controle sejam ensaiados. Disto resulta que os hábitos a eles correspondentes possam ser mais adequadamente adquiridos, de modo a aumentar as chances de comportamento bem sucedido. $\mathrm{O}$ aspecto de exercício, de ensaio, envolve situações que, em um ambiente especial, simplificado, simulem situações reais ou possíveis, em que os sujeitos, ou individualmente ou em cooperação, precisam guiar-se de modo a lançar mão dos movimentos, atividades, energias e outros meios, a fim de terem sucesso na satisfação de suas demandas.

Mas, e no caso de outro tipo de ambiente, bem mais complexo, onde a interação e o sucesso dos indivíduos dependem da comunicação, e de uma série cada vez maior de informações veiculadas em linguagem? Onde a linguagem representa, ordena, intervém de modo a compor um enorme sistema de crenças, expressões, situações, vivências; em resumo, uma enorme herança comum que, como se não bastasse sua vastidão, ainda muda em ritmo cada vez mais acelerado a cada geração? Falamos do ambiente cultural. Aqui, a capacidade de raciocínio e de comunicação, a capacidade de sintonizar-se com os interesses e crenças dos outros sujeitos e favorecer-se desta integração, substituem a força e agilidade físicas. E onde o mecanismo de controle da força tem o seu substituto? Controle é, neste caso, controle intelectual: controle sobre os significados. O controle é a inteligência dirigida aos objetos do pensamento e do discurso. Em 
sua melhor forma, ela se expressa por meio dos hábitos do pensamento reflexivo.

A força para realizar a decifração das estruturas simbólicas, para alguém ser capaz de interpretação do significado das mensagens escritas, efetua-se sob controle do pensamento que investiga, analisa e reflete. Investigação, antecipação, reflexão são termos que se referem propriamente aos mecanismos de controle que ordenam e integram os hábitos, na forma de um comportamento mental bem-sucedido, bem-adaptado ao ambiente social contemporâneo. Um ambiente onde a informação é abundante e veloz. Uma das preparações, conforme se dizia acima, importante principalmente para os mais jovens, é participar de situações em que estes mecanismos de controle sejam ensaiados, para que os hábitos a eles correspondentes possam ser mais adequadamente adquiridos, de modo a aumentar as chances de comportamento bem sucedido. Só que aqui não se trata de controlar o corpo, e sim de interpretar estruturas de linguagem. Numa palavra: ler.

Estas situações ambientais são, ambas, descrições parciais. Juntas podem ser uma maneira plausível de compreender a condição humana. O ser humano habita, indubitavelmente, o ambiente natural, com seu corpo físico submetido às leis naturais. Com a mesma razão se afirma que habita um ambiente social, composto dos produtos combinados das mentes humanas, veiculados nesta estrutura de infinitas possibilidades que é a linguagem.

\section{Considerações finais}

O percurso aqui empreendido tentou situar a leitura em seu devido lugar no conjunto de condutas pelas quais um indivíduo se afirma e se desenvolve como agente ativo no ambiente social de que faz parte. Por isso, insistiu no texto como artefato e na leitura como investigação e como comunicação de significados. Fez esta tentativa seguindo as indicações fornecidas pelo estudo da obra de um pensador cuja atenção aos temas da educação, do pensamento e da comunicação é reconhecida amplamente pela comunidade dos que se interessam por tais temas. Espera-se que a identificação da leitura com o pensamento reflexivo e, portanto, com um 
legítimo fim educacional, contribua para uma compreensão naturalística da leitura. Assim como se espera que contribua para uma abordagem crítica da filosofia de Dewey, tendo como pano de fundo o ambiente contemporâneo. Este ambiente, em tempos recentes, está cada vez mais carregado de informação, e os usos da linguagem, por meio dos projetos tecnológicos de diversos tipos, ultrapassam os limites físicos tradicionais de veiculação do texto escrito. Justamente, por isso, vale insistir neste uso tão fundamental e tão familiar da inteligência, que é a leitura.

\section{Referências}

BIESTA, Gert. 'Of all affairs, communication is the most wonderfull': the communicative turn in Dewey's Democracy and education. In:

John Dewey and our educational prospect - a critical Engagement with Dewey's democracy and education. Albany: State of New York University Press, 2006.

DENNETT, Daniel. The interpretation of texts, people and other artifacts. Philosophy and phenomenological research, v. 50, p. 177-194, SupplementFall, 1990.

DEWEY, John. Democracia e educação: introdução à filosofia da educação. São Paulo: Nacional, 1959.

. How we think. New York: Dover, 1997 (1910, 1. ed.).

2. ed.). . Como Pensamos. São Paulo: Cia Editora Nacional, 1979. (1933,

KILPATRICK, William. Educação para uma civilização em mudança. São Paulo: Melhoramentos, 1978.

MATOS, José Claudio. Educação como adaptação: A experiência segundo John Dewey. Filosofia e Educação, Campinas, v. 3, n. 2, p. 481-501, Out. 2010.

MORAIS, José. A Arte de ler. Lisboa: Edições 70, 2002.

Data de registro: $13 / 10 / 2011$

Data de aceite:03/10/2012 